Teaching \& Learning (2011) 6(1), 15-27

\title{
Facebook and Teacher Knowledge Development: An Examination of How Teachers Are Using Facebook Groups to Support their Knowledge Development
}

\author{
DR. CAMILLE RUTHERFORD \\ Brock University
}

\begin{abstract}
In recent years, Facebook has proven itself to be a popular gathering space, not just for college students, but also professionals seeking an opportunity to network with others and exchange ideas and resources. Within these gathering areas are thousands of teachers who can be observed engaging in discussions related to teaching and learning. The findings of this research indicate that much of what is occurring within these discussion groups can be considered a pragmatic attempt to enhance teacher knowledge development.
\end{abstract}

\section{Purpose}

In recent years, Facebook has proven itself to be a popular gathering space, not just for college students, but also professionals seeking an opportunity to network with others and exchange ideas and resources. Within these gathering areas are thousands of teachers who can be observed engaging in discussions related to teaching and learning. The vast size of these individual groups, that number in the tens of thousands, and the hundreds of discussion topics that cover the spectrum of education issues, can make it quite daunting for researchers to make sense of what is taking place. The intent of this research is to examine how teachers are using Facebook as a means to support knowledge development, and to determine if Shulman's (1987) categorization of teacher knowledge can be used to frame this phenomenon and successfully describe what has occurred.

\section{Significance}

From a broad perspective, the vast and uncharted waters of online social networks remains to be explored as scholars currently have a limited understanding of who is using these sites, and why they are being used (boyd \& Ellison, 2007). This need for research is exacerbated by the dramatic growth of these sites and their hundreds of millions of users (Beer, 2008; boyd \& Ellison, 2007; Golbeck, 2007). With close to 100,000 participants, the sheer number of teachers 
who are engaging in the various Facebook teacher groups, makes it imperative that researchers comprehend this occurrence and begin to determine its possible impact on teacher knowledge. This avenue of research can then lead to an exploration of the impact of informal online knowledge development on teaching and learning.

\section{Theoretical Framework}

This exploration of teacher knowledge development within the context of Facebook, is guided by the literature related to teacher knowledge development with a focus on Shulman's categorization of teacher knowledge. Shulman's work in the area of teacher knowledge can be considered seminal (Ball, Thames, \& Phelps, 2008; Borko \& Putnam, 1986), as he has made "fundamental contributions that have deeply impacted educational research, policy, institutional practices and teacher education in science and mathematics worldwide” (Hutchings, 2004).

As a reaction to the reform minded research of the 1980s that stressed the professionalization of teaching and the formulation of a knowledge base for teaching. Shulman's notable contributions to the research community's understanding of teacher knowledge began in 1986 with his AERA presentation that highlighted the need for a more coherent theoretical framework for addressing teacher knowledge. This presentation was later published as an article in Educational Researcher, titled "Those who understand: Knowledge growth in teaching." His frequently cited 1987 paper that served to further categorize this knowledge base, followed his initial entrée into the development of a framework of teacher knowledge. The seven categories that are fundamental to acquiring the knowledge needed to promote comprehension among students grew out of the existing literature, regarding the qualities and understandings, skills, and abilities, and traits and sensibilities that render someone a competent teacher (Shulman, 1987). Shulman's (1987) categories are as follows:

- Content knowledge, begins with a teacher's understanding of what is to be learned.

- General pedagogical knowledge, with special reference to those broad principles and strategies of classroom management and organization that appear to transcend subject matter.

- Curriculum knowledge, with particular grasp of the materials and programs that serve as "tools of the trade" for teachers.

- Pedagogical content knowledge, that special amalgam of content and pedagogy that is uniquely the province of teachers, their own special form of professional understanding.

- Knowledge of learners and their characteristics

- Knowledge of educational contexts, ranging from the workings of the group or classroom, 
the governance and financing of school districts, to the character of communities and cultures.

- Knowledge of educational ends, purposes, and values, and their philosophical and historical grounds.

While there is no single system for the categorization of teacher knowledge, frameworks such as Shulman's provide a useful analytic tool for thinking about teacher knowledge (Borko \& Putnam, 1986). Shulman's (1987) categorization was chosen not just because it can be considered the seminal piece that prompted considerable interest and research into the area of teacher knowledge (Ball et al., 2008; Gess-Newsome, 1999; Verloop, Van Driel, \& Meijer, 2001), but its genesis grew out of the same need as this investigation into educator Facebook discussions - the need to simplify an otherwise complex activity (Shulman, 1986).

\section{Facebook}

While it was not the first major social network site to appear, Six Degrees.com was created in 1997, nor is it the largest network, as MySpace has more users, Facebook with its 80 million users has come to dominate discussions related to social network sites (boyd \& Ellison, 2007). Facebook was created in 2004 at Harvard University, as a means to facilitate student interaction and communication. It has since grown into an enormously popular "social utility that helps people communicate more efficiently with their friends, family and coworkers” (Facebook, 2008).

Central to the Facebook experience are the user created profiles where one can post descriptive details about themselves, as well as pictures and video. These detailed descriptions facilitate the creation of social networks of 'friends'. It is the ability to seek out and connect with old or new friends that has fueled Facebook's exponential growth (boyd \& Ellison, 2007). While the site includes a number of other features, of paramount importance to this research is the Facebook Groups application. This feature allows each user to join and create up to 200 groups that are based on shared interests and activities (Facebook, 2008). A group can be public, where anyone can join, or private, where the group’s administrator moderates its membership.

A keyword search on the site for the word 'teacher' indicates that there are over 500 groups with teacher in its title. While many of these teacher groups are teacher fan or non-fan clubs that congregate around their like or dislike of a specific teacher, many are a gathering of educators that are interested in connecting with other educators to share ideas and resources (see 
Table 1). These teacher groups range from large collections of tens of thousands of members, from diverse locations, to small groups that have a pre-existing offline relationship.

Table 1

Facebook group examples

\begin{tabular}{lc}
\hline \multicolumn{1}{c}{ Facebook Teacher Discussion Groups Descriptions } & Number of Participants \\
\hline $\begin{array}{l}\text { You know you're a teacher when... A group for all those who are in } \\
\text { the "rewarding" (i.e. doesn't pay well!) profession of teaching or }\end{array}$ & 38,504 \\
training to be a teacher & 28,374 \\
\hline Primary Teachers - Resources, ideas, stress relief!: Basically, I & \\
was planning today and thought why not set up a group for all those & \\
primary teachers out there where we can share resources, good & \\
websites, ideas and general stories to relieve the almighty stress & \\
that is being a primary school teacher!! & \\
\hline Ontario teachers - resource and idea sharing: As Ontario & \\
teachers, we have a wealth of experience and useful ideas to share. \\
We know what works, and what does not work. Let's share what we \\
have discovered! \\
\hline Teacher Ideas for all ages!!!! Sharing fun activities, useful \\
information, ideas with other teachers. Preschool-5th grade \\
\hline $\begin{array}{l}\text { Beginning Teacher: A group for those in their first few years of the } \\
\text { teaching profession, to share ideas, offer support, etc. Also a group } \\
\text { for those who will soon be entering the teaching profession and are } \\
\text { interested in what those beginning years are actually like }\end{array}$ \\
\hline
\end{tabular}

The ability to connect with other members is facilitated by the presence of a member list that includes each member's name, their profile picture, and a link to request to be added to their friend list. In addition to these networking features, each group page includes picture and video sharing applications that permit users to share these resources with the entire group.

Intra-group communication takes place via a word wall, where members can post general messages directed to the group as a whole, or within a discussion forum. The highly utilized discussion feature allows users to engage in specific conversations regarding a user-defined topic. It is these exchanges that take place within the discussion feature that are at the centre of this research.

\section{Methodology/Data Sources}

Central to this investigation will be a qualitative and quantitative examination of the discussion topics and responding messages of a Facebook teacher group. Shulman's (1987) categorization of teacher knowledge will be used to categorize the discussion topics from the 
'Ontario Teachers, resource and idea sharing group.' This moderately sized group, with over eight thousand members, created 249 discussion topics over the course of the 2007/2008 school year. The contents of the opening discussion post have been used to categorize the discussion topics, while the frequency of the category occurrence was noted in an attempt to determine which categories dominated the discussions.

To be included in this study, a discussion had to consist of at least two posts by two different people. Opening posts that received no response were excluded, as without the input of another individual, it cannot be considered a discussion. The 62 solo posts that were excluded from this study were often thinly disguised marketing attempts by authors, website developers or salespeople trying to draw users to their external websites. It is important to note that even though these posts did not attempt to engage users in a discussion, many of these solo posts were still related to the education process.

Once the solo posts were excluded from the sample, 187 opening discussion posts were coded, using Shulman’s (1987) categorization of teacher knowledge and two additional codes. The code of “other” was used when Shulman’s (1987) categories could not be adequately applied to discussion topics (see Table 2).

After an initial review of the opening discussion posts, it became apparent that there was a significant number of posts that pertained to teacher employment. While these posts were germane to the 'Knowledge of Educational Context' category, which includes knowledge of school district administration, the author thought it would be prudent to create an additional category of 'Employment.' Consequently, in addition to Shulman's (1987) seven categories of teacher knowledge, the two additional codes of 'Other' and 'Employment' were also used (see Table 2). 
Table 2

Coding Categories

Coding Categories in Alphabetical Order

Content Knowledge

Curriculum Knowledge

Employment*

General Pedagogical Knowledge

Knowledge of Educational Contexts

Knowledge of Educational Ends

Knowledge of Learners

Other*

Pedagogical Content Knowledge

${ }^{\star}$ Author created category

A qualitative coding program called HyperResearch was used to facilitate the coding process. The text of each discussion was copied from the Facebook site and saved as a separate text file. These files were imported into HyperResearch, where the text of the initial discussion post was reviewed, and then coded by the author. A report of the discussion text and its assigned code were then exported into an Excel spreadsheet, so that the quantitative analysis could take place.

An additional researcher coded a randomly chosen sub-set of the discussion posts to determine the level of inter-rater reliability for the coding process. After coding 50 discussion posts, the percentage of agreement was 80 percent. This can be considered an excellent level of agreement, and indicates a high degree of consistency for the coding process (Fleiss, Levin, \& Paik, 2003).

\section{Findings}

The code that was most frequently applied was that of Pedagogical Content Knowledge. With 49 posts, this made up 26.2 percent of the initial discussion posts (see Table 3). This code was applied to posts that were related to participants seeking advice and ideas about how to make their lessons for a specific subject more creative, engaging, interactive, or fun. 
Facebook and Teacher Knowledge Development

Table 3

Category Frequency

\begin{tabular}{lcc}
\hline & $\begin{array}{c}\text { Number of Opening } \\
\text { Discussion Posts }\end{array}$ & Percent \\
\hline Pedagogical Content Knowledge & 49 & $26.2 \%$ \\
Employment & 42 & $22.5 \%$ \\
Curriculum Knowledge & 37 & $19.8 \%$ \\
General Pedagogical Knowledge & 18 & $9.6 \%$ \\
Other & 17 & $9.0 \%$ \\
Knowledge of Educational Contexts & 16 & $8.5 \%$ \\
Knowledge of Learners & 5 & $2.7 \%$ \\
Content Knowledge & 3 & $1.6 \%$ \\
Knowledge of Educational Ends & 0 & 0 \\
\hline
\end{tabular}

The two following quotations represent the typical Pedagogical Content Knowledge posts that sought ideas and activities for a specific subject area:

Does anyone have some creative ideas for the liquids and solids unit? I would appreciate anything you can throw my way!!!

I'm starting Chapter 6 of the Grade 6 Nelson textbook (multiplication/division) and was wondering if anyone had any great lesson ideas for the first topic (factors/multiples, etc.)

Coming in a close second with 42 opening discussion posts, the Employment code was applied to 22.4 percent of the posts. This subset of the Knowledge of Educational Context category was applied to posts that were related to the process of securing employment as a teacher, or gaining admission to a teacher education program. Unlike many other jurisdictions, the Canadian province of Ontario has a significant surplus of teachers to fill a limited number of jobs. As a result, a large number of posts in this category expressed frustration about securing a full time teaching position. The following two quotations are examples of posts from the employment category:

I'm finding it incredibly difficult finding full time teaching work in Ontario. Is anyone else experiencing this? Unless a PJ teacher has their french qualifications, then it doesn't seem like full time \& permanent work is a realistic goal. Having family members (or good friends) working in a board also seems to help.

I was just wondering if anyone had any tips on what type of questions will be asked in an interview for the supply list (public and catholic)? Any help would be greatly appreciated.

In contrast to the Pedagogical Content Knowledge posts, where the users were soliciting ideas related to a specific content area, the 37 Curriculum Knowledge posts were most often 
seeking curricular resources for a specific subject area and grade level. The educators who created these types of posts were frequently seeking online resources or recommendations of helpful websites. The following posts seeking curricular resources typify the posts that were coded as Curriculum Knowledge:

One of my grade 6 students has asked for help in improving his handwriting as others often have trouble reading it. He is turning over a new leaf in school, so I want to encourage him any way I can, but don't know which resources to use for handwriting for older students. Does anyone know of any resources for this?

I just accepted a position at a private high school, and I will be teaching gr. 9 and 10 french. French is not one of my teachables, but I have taken several french classes at college. Does anyone have any online resources or good books that will help me teach these two grades.

The 18 opening discussion posts that were coded as General Pedagogical Knowledge, were those that were related to the general knowledge of principles and strategies for curriculum and classroom management. The majority of these posts sought advice related to classroom management. These posts often pertained to educators seeking advice in dealing with specific behavioural challenges. The two posts that follow are examples of General Pedagogical Knowledge posts that highlight a desire to find new strategies to cope with the challenges of classroom management:

I have a student who tries to bait everyone all the time. When I say no to something, he tries to debate the validity of the rule. He seems to need a valid reason for everything, but I just don't have the time to explain everything all day long ... I have 25 other students who need my attention. He's very bright and refuses to do work, knowing that he'll pass anyway. I've spoken one on one and asked whether this is acceptable at home, he said no and added that he does it at school because he can get away with it here. Any suggestions?

I've just landed a job teaching math and science to a grade 7/8 split and to a grade 9 class on a first nations reserve. Very small classes with very big behavioural issues and about half on IEPs, mostly for reading LDs, who have had a succession of supply teachers since September. These kids are bouncing off the walls. My main worry is classroom management; what sort of plan can I implement that will encourage these kids to work with me to create a productive learning atmosphere?

The code of "Other” was applied to any discussion post that did not adequately fall under any of Shulman's (1987) categories. While the 17 opening discussion posts that received this 
Facebook and Teacher Knowledge Development

code may be related to the educational process, they do not readily address any component of teacher knowledge. The two following posts are examples of the types of posts that were coded as Other:

I'm teaching a 5/6 class and would love to give them something small for Christmas, but I am having a hard time thinking of cheap ideas for this age group. Does anyone have any ideas? Thanks!

I'm looking for old magazines for a school project. They don't have to be in good condition, since I'm mostly interested in the covers. I would prefer not to print covers off the internet, as I'm trying to recycle/re-use unwanted magazines. If you know where in Ottawa I could obtain old magazines free of charge, or if you have old magazines you'd like me to take off your hands, please post here or send me a message.

As noted earlier, opening discussion posts that fell under the category of Knowledge of Educational Contexts were sub-divided to create a new sub-category of Employment. The remaining 16 posts addressed issues pertaining to teacher knowledge of school or school district administration or policies. The following Knowledge of Educational Contexts posts are prime examples of posts that were related to school policy or school district administration:

How much of your own money did you spend on classroom decorations and materials when you started your first full time position? What kind of materials and funds did the school start you off with?

I have heard rumblings from teachers in other boards that some boards are looking to add a November break to the school term, a la, the university/college reading week. I am curious to see other teachers' opinion about this, both pro and con, as I think it may be a good idea but know that there are definite draw backs. I personally remember how much I appreciated the break at university, it came at a time right before "the crunch" hit and was a great stress reliever. I always felt refreshed and ready to return. I also think it would be a great travel option for parents who take their children out of school before Christmas because it is cheaper to travel, this way all of the students would be gone at the same time, rather than 2 one week and 3 the next. What do you think? Is adding a November break a good option?

The 5 discussion posts that were coded as pertaining to Knowledge of Learners \& their Characteristics were typically attempts to seek general advice and information about working with students with special needs, but did not request specific strategies or materials. The posts were often about developing a greater understanding about the needs or characteristics of ESL, 
Aboriginal, or special education students:

I'm a grade 5 teacher who was just informed today that I will be doing planning time coverage 2-3 periods a week in our ASD classroom. Does anyone have any suggestions or ideas, or what I can do with the students?

I'm teaching a 1/2/3 split in a very small school in a remote Northern community of Ontario. Mainly Native population, largely low levels academically, and a whole lot of behavioural stuff. Any ideas about anything at all would be awesome!

The 3 opening discussion posts that were coded as being related to Content Knowledge, pertained to an educator's need to enhance their own knowledge of a specific content area. The following is an example of this type of discussion post:

Help!! I found out that I will be teaching the recorder during my practicum. I don't play any instrument nor did I ever learn to read music! Can anyone suggest a good resource that I can use to quickly teach myself the basics then teach the grade 5 s with?

There were no discussion posts that were coded, as a Knowledge of Educational Ends. This code would have been applied to any posts that were related to the purposes, values and philosophical and historical grounds of education.

\section{Discussion}

Simply perusing the teacher related discussion forums on Facebook could lead one to note that in contrast to the website's reputation as being the preferred medium for teenage gossip and reconnecting with long-lost friends, these forums also house the professional interactions of educators that may replicate the discussions that once took place in the staffroom. A more sophisticated investigation will reveal that these discussions are more than idle teacher chatter, and represent hundreds of pragmatic attempts to enhance teacher knowledge in a nonjudgmental, low risk environment.

With 91 percent of the post falling under Shulman's (1987) categorization of teacher knowledge, it is evident that these discussions are relevant and have the potential to impact teaching practice. Shulman's categories were based on his observations of teachers that displayed expertise in teaching. He noted that these categories should form the knowledge base of what a teacher should know and be able to do (Shulman, 1987). Following Shulman's initial foray into teacher knowledge categorization, iterations of his categories were used by the 
National Board for Professional Teaching Standards in the United States (Hargreaves, 2006), to outline the categories of teacher knowledge that are necessary to promote student comprehension (Shulman, 1987). Consequently, these Facebook discussions should be seen as enhancing the participants’ ability to acquire the knowledge necessary to support student learning.

With over a quarter of the posts being coded as Pedagogical Content Knowledge, the findings of this exploration lends support to Shulman's assertion that pedagogical content knowledge is vital to overall teacher knowledge. Shulman's work emphasized the importance of pedagogical content knowledge rather than content knowledge, as pedagogical content knowledge highlights a teacher's understanding of how particular topics, problems, or issues are organized, represented, and adapted to the diverse interests and abilities of learners and presented for instruction. With the ability to influence student learning, pedagogical content knowledge has been identified as being vital to overall teacher knowledge, and is perceived to have the greatest impact on teachers’ classroom actions (Ball et al., 2008; Gess-Newsome, 1999; Shulman, 1986, 1987; Verloop et al., 2001). Thus, the number of Facebook discussions that were coded as being related to pedagogical content knowledge, highlights the important role these types of discussions can play in teacher knowledge development, and may serve to explain why so many teachers are engaging in this specific type of discussion.

The large proportion of discussion posts that adhere to at least one of Shulman's (1987) seven categories, demonstrates the usefulness of this categorization to make sense of online teacher discussions. If a large portion of the posts had been coded as 'Other,' it would have been evident that another system of codification would have been necessary. The greatest challenge to determining the usefulness of Shulman's framework was the overlap of some of the categories. While the lines of delineation between the categories can at times become blurred, frameworks such as Shulman's still provide a useful analytic tool for investigating teacher knowledge (Borko \& Putnam, 1986).

\section{Conclusion}

In addition to becoming one of the most popular social gathering places on the planet, Facebook has also become a notable professional forum. The popularity of this new medium contributes to the daunting nature of pursuing a scholarly investigation into what has taken place. With tens of thousands of members creating thousands of discussion posts, a means of 
categorization is necessary to make sense of the reams of data that are being created. Since Shulman's (1987) categories were successfully used to code over 90 percent of the opening discussion posts, this investigation clearly demonstrates the usefulness of using Shulman's (1987) categorization of teacher knowledge, as a framework to enhance our understanding of teacher online discussions.

As well as highlighting the use of Shulman's (1987) categories as an effective sorting mechanism, this research documents that much of what is occurring within these discussions can be considered teacher knowledge development. The number of posts that initiated a dialogue related to the resources, ideas, and strategies needed to improve teaching practice, should lead one to conclude that many educators are turning to Facebook teacher groups, in an attempt to unpack "what makes the learning of a specific topic easy or difficult” (Shulman, 1986 p. 9. This fact in and of itself can be considered significant, as many consider Facebook to be the hangout of gossiping teens, and have not realized that it could be seen as a supplement to traditional teacher professional development. Instead of dissuading teachers to join Facebook, school districts and teachers' unions should encourage, and even support, teacher Facebook participation in this non-judgmental, low risk forum. By encouraging formal and informal teacher leaders to participate in these discussions, they could ensure that these online discussions are being supplied with the knowledge and resources available to experienced teachers that have been shown to support best practices for teaching and learning.

The institutions and individuals engaged in teacher training and support, should consider the benefits of periodically reviewing the teacher discussions on Facebook, as a means to gauge the needs of teachers. Teacher mentors, school administrators, and teacher education programs should be attuned to what is being discussed in these groups, as it may provide valuable insight into the challenges many teachers are coping with, but are not being addressed in a traditional manner. Further research into why educators are turning to Facebook to supplement their knowledge, may enable school districts, teacher unions and teacher education institutions, to proactively fill some of these knowledge gaps that are currently being filled by Facebook discussions. 


\section{References}

Ball, D., Thames, M., \& Phelps, G. (2008). Content knowledge for teaching: What makes it special? Journal of Teacher Education, 59(5), 398-407.

Beer, D. (2008). Social network(ing) sites...revisiting the story so far: A response to danah boyd \& Nicole Ellison. Journal of Computer-Mediated Communication, 12, 516-529.

Borko, H., \& Putnam, R. (Eds.). (1986). Learning to teach. New York: Macmillan.

boyd, d., \& Ellison, N. B. (2007). Social Network Sites: Definition, History, and Scholarship. Journal of Computer-Mediated Communication, 13(1).

Facebook. (2008). Facebook Factsheet. Retrieved from http://www.facebook.com/press/info.php?factsheet

Fleiss, J. L., Levin, B., \& Paik, M. C. (2003). The measure of interrater agreement. In W. A. Shewart \& S. S. Wilks (Eds.), Statistical methods for rates and proportions (3rd ed.) (pp. 598-626). San Francisco: John Wiley \& Sons.

Gess-Newsome, J. (Ed.). (1999). Pedagogical content knowledge: An introduction and orientation. Netherlands: Kluwere Academic Publishers.

Golbeck, J. (2007). The dynamics of web-based social networks: Membership, relationships, and change. First Monday, 12(11), 18.

Hargreaves, A. (2006). Towards a social geography of teacher education. In D. Hartley \& M. Whitehead Teacher Education: Major themes in education volume 5 globalisation, standards and teacher education, (pp. 227-254). London: Routledge.

Hutchings, P. (Ed.). (2004). Teaching as community property: Essays on higher education / Lee S. Shulman. San Francisco, CA: Jossey-Bass.

Shulman, L. S. (1986). Those who understand: Knowledge growth in teaching. Educational Researcher, 15(2), 4-14.

Shulman, L. S. (1987). Knowledge and teaching: Foundations of the new reform. Harvard Educational Review, 57(1), 1-22.

Verloop, N., Van Driel, J., \& Meijer, P. (2001). Teacher knowledge and the knowledge base of teaching. International Journal of Educational Research, 35(5), 441-461. 